\title{
QUANTITATIVE AND QUALITATIVE ANALYSIS OF JOINT STIFFNESS IN NORMAL SUBJECTS AND IN PATIENTS WITH CONNECTIVE TISSUE DISEASES* ${ }^{*}$
}

\author{
BY
}

\author{
VERNA WRIGHT‡ AND RICHARD J. JOHNS§ \\ From the Applied Physiology Division, Department of Medicine, Johns Hopkins University School \\ of Medicine and Hospital, Baltimore, Maryland
}

Rheology is the study of the deformation and the flow of matter. In the present communication this science is applied to the human joint, its motion, and the forces resisting joint motion.

The techniques used to measure joint stiffness have long been used by physicists, physical chemists, and engineers in studying the stiffness of a wide range of materials. Such studies have been of particular use in two areas: They have provided a quantitative measure of stiffness in precise physical terms, and they have defined qualitatively the different parameters contributing to total stiffness. This latter type of analysis has been important, for example, in studies of the cross-linking in elastic polymers.

Both types of study have been employed in this investigation. Rheological techniques have been used to measure alterations in joint stiffness produced by physiological changes, pathological disorders, and therapeutic methods, and it is expected that a detailed study of the parameters contributing to total stiffness will give information on alterations in the materials of which joints are made.

\section{Methods}

The apparatus used has been described in detail elsewhere (Wright and Johns, 1960a). In principle, the force required to impose a given motion on the joint was recorded; this was the force required to overcome joint stiffness. The second metacarpophalangeal joint was moved sinusoidally at various amplitudes and frequencies of rotation. The torque (in gram-centimetres) required to impose this motion was displayed

\footnotetext{
* This work was aided by grant B-894 (C3) from the Division of Neurologic Diseases and Blindness, National Institutes of Health, U.S.P.H.S.

$t$ Presented in part at a meeting of the Heberden Society on July 2,1960 .

\pm Present address: Department of Clinical Medicine, General Infirmary, Leeds.

$\S$ Kenny Foundation Scholar.
}

on both vertical axes of a dual beam cathode ray oscilloscope. The amplitude of rotational displacement (in radians) was displayed on the horizontal axis of one beam, and the rotational velocity (in radians per second) on the horizontal axis of the other beam. Loops relating torque to displacement and torque to velocity were thus traced on the oscilloscope, and representative displays were photographed.

These data were obtained in part by using the apparatus originally described in which the sinusoidal motion was derived from a pendulum, and in part by a crank driven by a variable speed motor (Fig. 1). This modification permitted investigation of a wider range of frequencies ( 0.003 to 3 cycles per second), velocities (15 radians pero second, maximum), and accelerations (280 radians? per second ${ }^{2}$, maximum).

Great care was taken in aligning the axes of rotation of the joint and the apparatus. Alignment was facilitated by an indicator extending from the finger holder to the axis of rotation of the finger (Fig. 2). Any toggle action was shown by the needle moving off centre, its tip being stationary when the joint was perfectly aligned. When these precautions were taken reproducibility of results was good. Measurements from series of records taken without moving the hand had a coefficient of variation of \pm 1.5 per cent. When the hand was removed from the apparatus and then replaced measurements showed a coefficient of variation of \pm 3.9 per cent.

\section{Theoretical Considerations}

Five types of stiffness were studied: elastic, viscous, inertial, frictional, and plastic.

(1) An elastic substance is one in which the stress (deforming force, or in this instance torque) is a function of the strain (deformation, or in this instance rotation). This is exemplified by an ideal spring in which the relationship is linear (Hookean, Fig. 3a), or by a rubber band in which the relationship is non-linear (nonHookean, Fig. $3 b$ ). The slope of the line relating torque and rotational displacement measures the elastic stiffness (gram-centimetres/radian). 


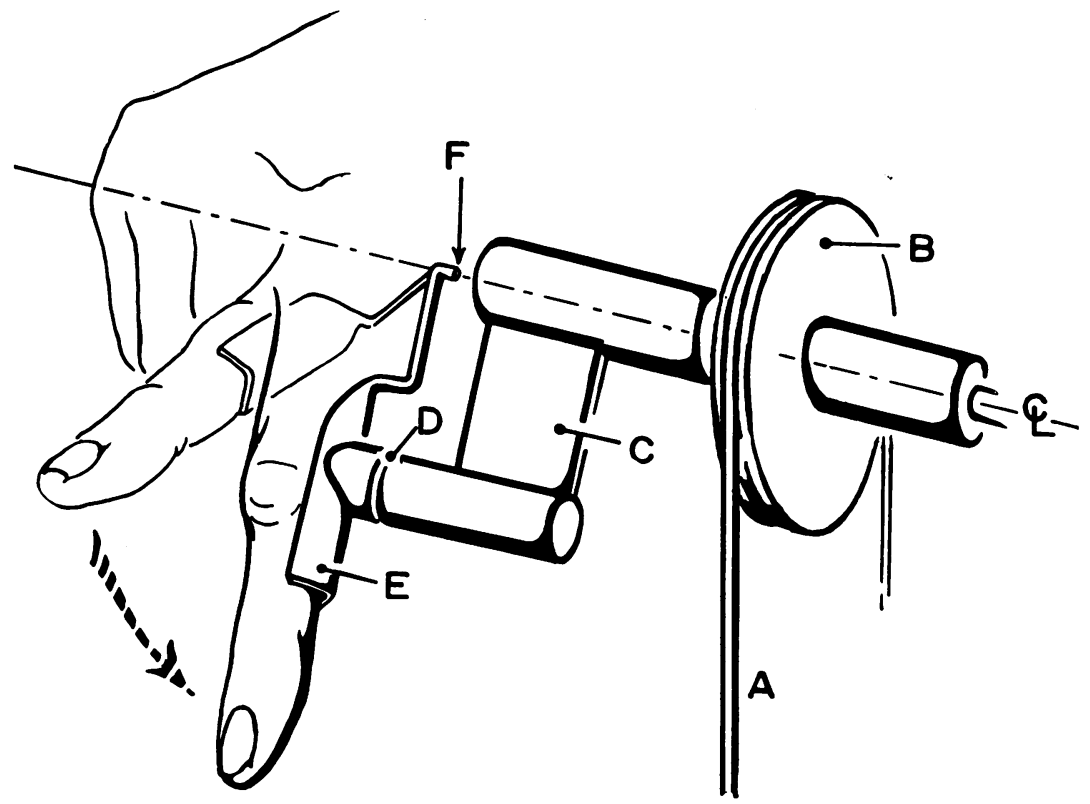

Fig. 1.-Modified apparatus:

A. Cable driven sinusoidally by a crank.

B. Pulley converting motion to sinusoidal rotation.

C. Lever transmitting torque to finger and on which strain gauges are bonded.

D. Swivel.

E. Finger holder.

F. Centre indicator.
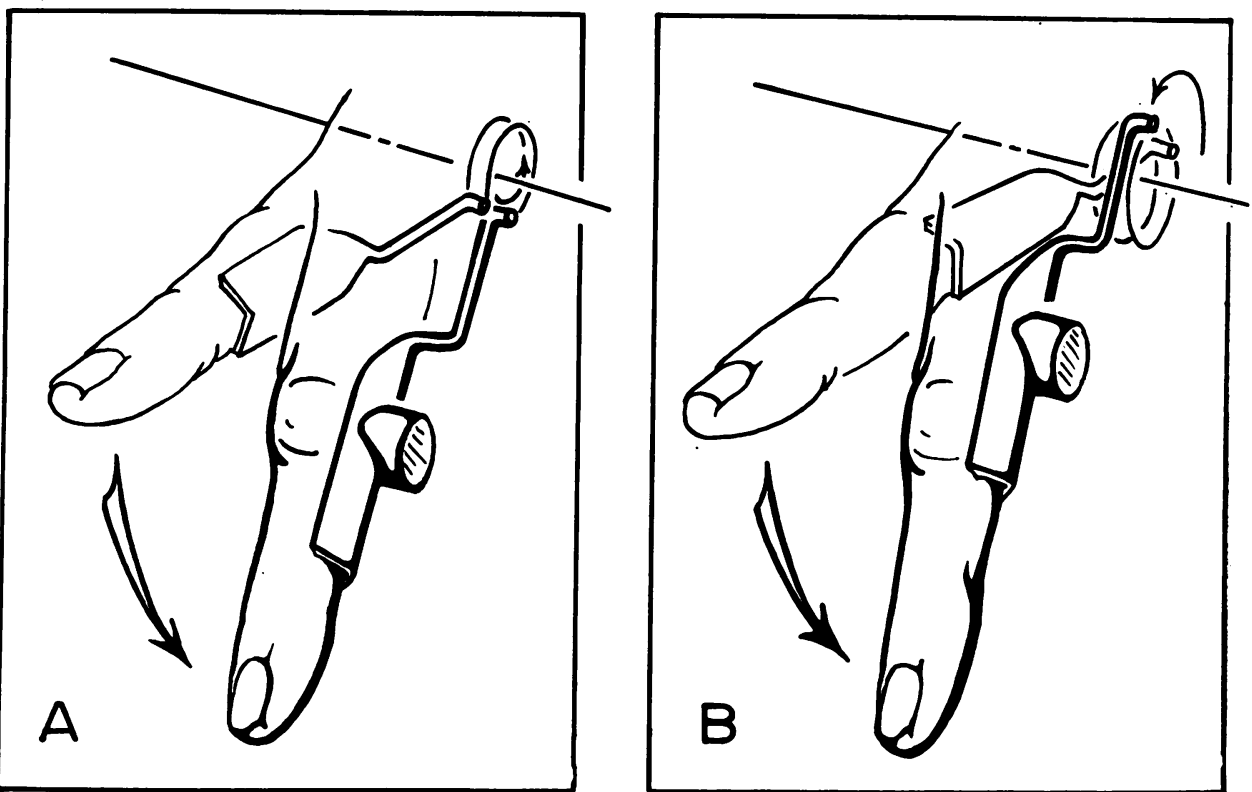

Fig. 2.-Centre indicator. The finger holder was removed from the apparatus and attached to the finger in such a position that the indicator tip was not displaced as the joint rotated. Holder rotates as in A when distally placed, and as in $B$ when proximally placed.

The holder was then attached to the apparatus and the hand so positioned that the indicator of the joint axis and that of the apparatus coincided. 
(A)
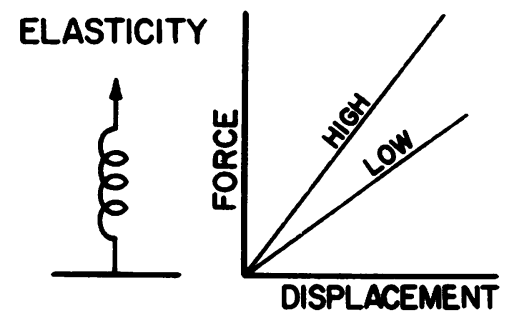

(C)
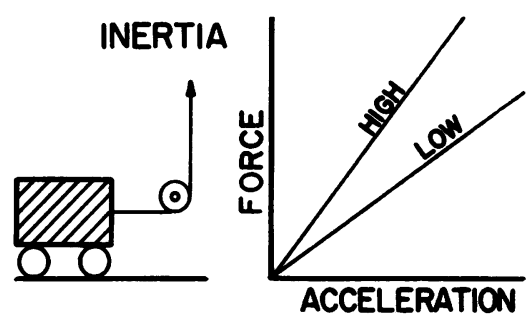

(E)

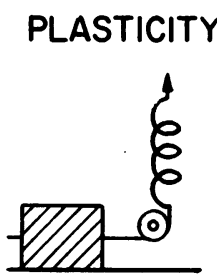

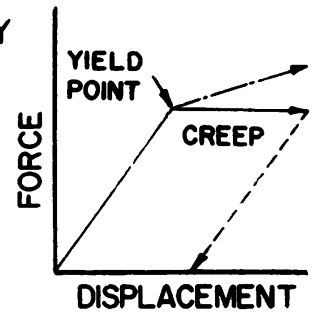

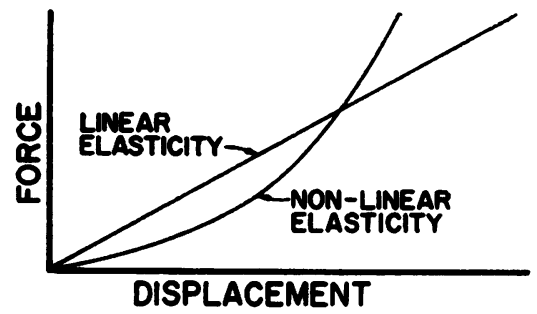

(B)
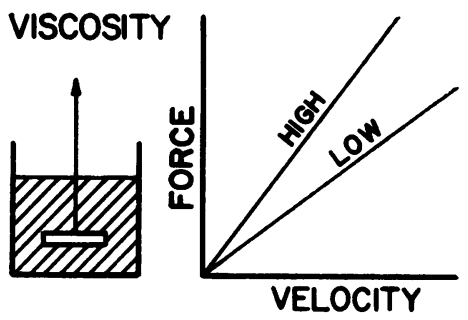

(D)

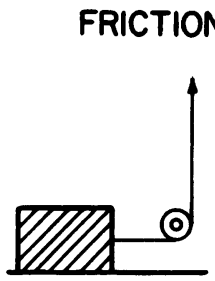

(F)

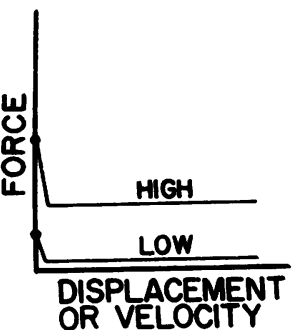

A. Elastic stiffness exemplified by an ideal spring, showing a linear relation between force and displacement. A stiffer spring exhibits a greater stiffness (steeper slope).

C. Inertial stiffness exemplified by a mass moving on frictionless bearings, showing a linear relation between force and acceleration.

E. Plastic stiffness illustrated by a spring attached to a frictional element. The yielding behaviour is described in the text.

(2) A viscous substance is one in which the stress (torque) is a function of the velocity. This is exemplified by a plate moving through an ideal viscous substance (Fig. $3 d$ ); the slope of the line relating torque and velocity measures the viscous stiffness (gram-centimetres/radian per second). There are both linear (Newtonian) and non-linear (non-Newtonian) cases.

(3) Inertial stiffness is exemplified by a mass moving on frictionless bearings (Fig. 3c). The force producing the motion is a function of the acceleration, and inertial stiffness is in this instance measured in terms of gramcentimetres/radian per second ${ }^{2}$.

(4) Torques due to frictional stiffness (Coulomb friction) are independent of displacement and velocity (Fig. $3 f$ ). Such stiffness is exemplified by a block moving over a rough surface. Engineers frequently
B. Linear and non-linear elasticity in which stiffness (slope) increases with displacement.

D. Viscous stiffness exemplified by a plate moving through an idea viscous fluid, showing a linear relation between force and velocity. Increased viscosity results in greater viscous stiffness (steeper slope).

F. Frictional stiffness exemplified by two opposing surfaces. The force is independent of displacement or velocity and is greatest at rest.

refer to a velocity dependent friction, lubricated friction. This is a combination of Coulomb friction and viscosity.

(5) Plastic stiffness is the most difficult to appreciate intuitively. This yielding or doughy stiffness may be exemplified by a St. Venant body, a spring connected to a block resting on a surface (Fig. 3e). As force is increased the spring elongates, and there is elastic behaviour up to a certain point (the yield point). With further displacement or with further application of force the block slides and there is progressive displacement with constant force (creep). Removal of the force is accompanied by only partial return to the initial displacement (broken line, Fig. 3e). This is termed incomplete strain recovery. Real substances with plasticity usually exhibit viscous properties above the yield point (dash and dotted line, Fig. $3 e$ ) as if a viscous element was attached to the left of the block. 


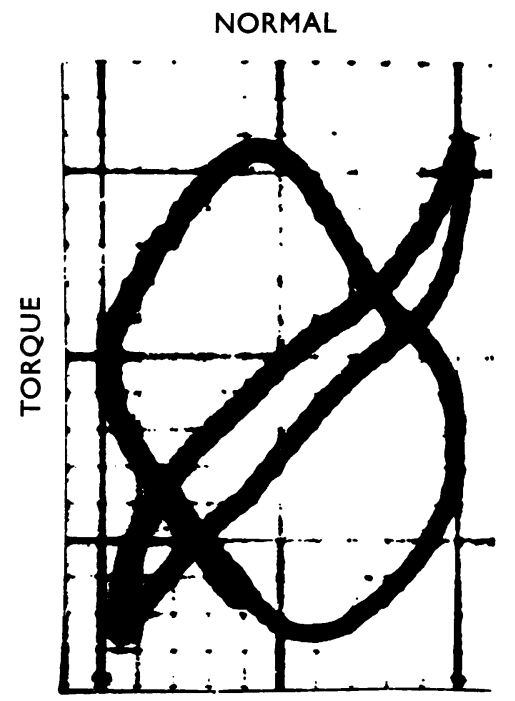

Fig. 4.- Normal record. The elliptical tracing relates torque to velocity (abscissa). The sigmoid curve exhibiting hysteresis relates torque to displacement (abscissa). Flexion is to the right.

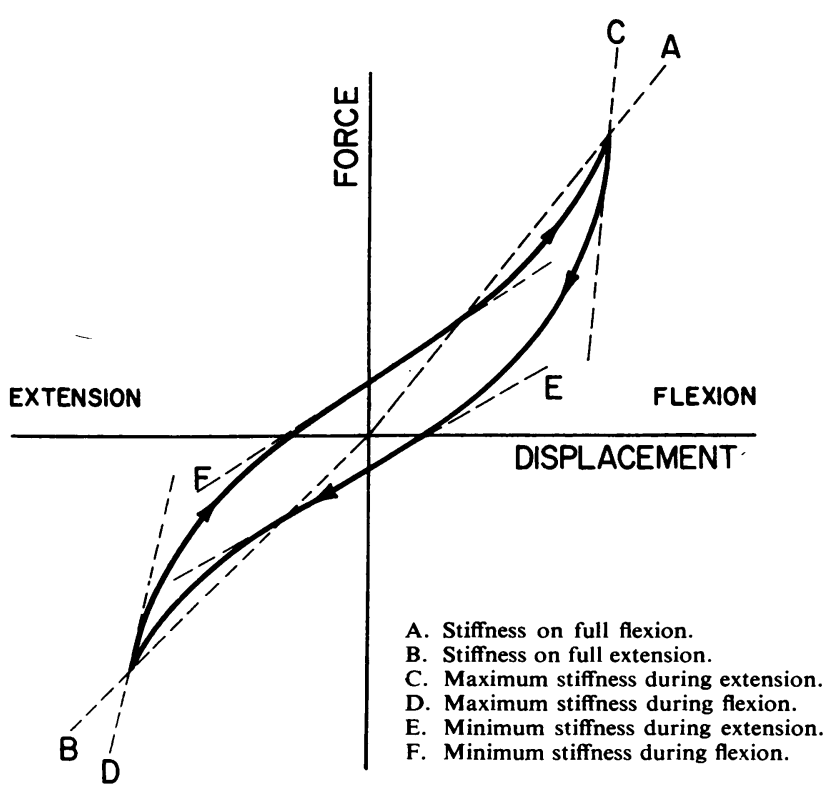

Fig. 5.-Diagram of joint stiffness showing slopes measured (broken lines).

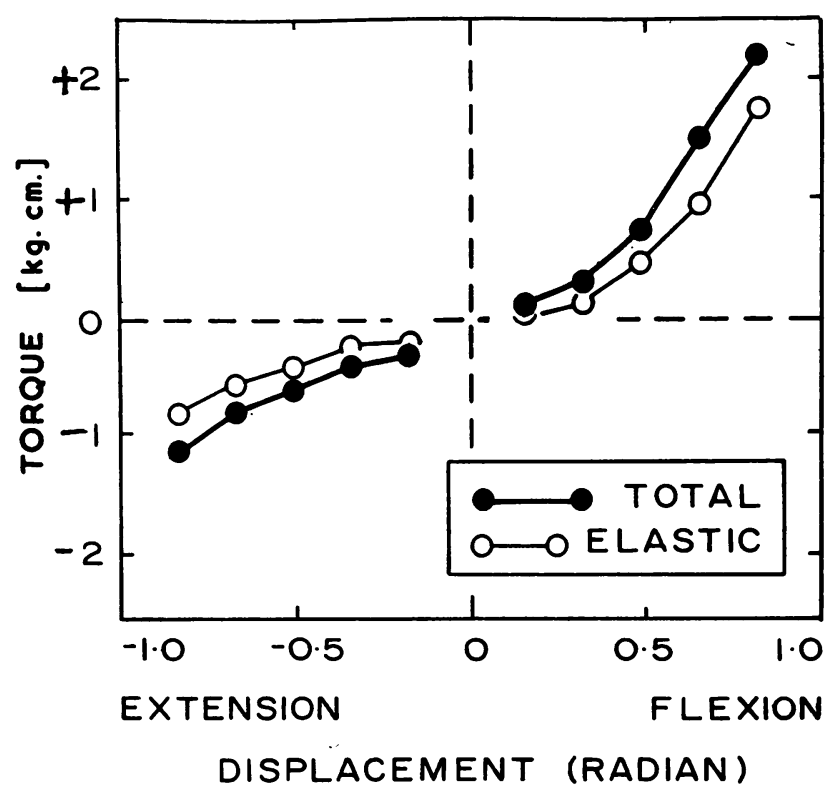

Fig. 6.- Relation of total and elastic stiffness to amplituc $>$ of rotation in a normal subject. There is a marked increase .n stiffness at larger amplitudes of rotation. These data were obtained from studies illustrated in Fig. 7 (overleaf). 
A tracing relating torque and rotational velocity is shown in Fig. 4. Viscous stiffness (gramcentimetres/radians per second) was determined by measuring the torque at maximum velocity. In sinusoidal motion, maximum velocity occurs at zero displacement, thus this torque was developed when the joint was in its mid position and was the torque required to overcome the sum of viscous stiffness and plastic stiffness.

Viscous stiffness was much smaller than elastic stiffness. The torque required to overcome total stiffness at maximum velocity was only one-tenth that needed to overcome elastic stiffness, and only a portion of this total stiffness was viscous stiffness.

In normal joints no torques attributable to friction could be demonstrated, even when a filter attenuating low frequencies was interposed in the torque measuring circuit. Such a filter permitted a 20 -fold increase in amplification of torque by attenuating torques due to elasticity and viscosity whose fundamental frequencies were below 10 c.p.s.

A study of inertial stiffness independent of other types of stiffness was possible by substituting for the finger a cylinder of the same configuration and mass $(27 \cdot 2$ g.). At accelerations below 56 radians per second $^{2}$ no torque due to inertial stiffness was measurable. Acceleration depends upon both frequency and amplitude of rotation. At maximum amplitude of rotation $\left( \pm 47^{\circ}\right.$, or \pm 0.833 radians) this acceleration is reached at a frequency of $1 \cdot 3$ c.p.s. At the usual amplitude $\left( \pm 29^{\circ}\right.$, or \pm 0.50 radians) a frequency of 1.7 c.p.s. is required to achieve an acceleration of 56 radians per second ${ }^{2}$.

Stiffness was also studied under transient rather than cyclical conditions. That is to say, the joint was displaced from the neutral position and held there, as opposed to the previously described methods in which the amplitude varied sinusoidally. Torque was recorded as a function of time on moving photographic film. Studies in all normal subjects revealed prominent stress relaxation (Fig. 7). ज़ Torque, or stress, waned with the passage of time. The final torque remaining after stress relaxation had run its course was solely attributable to elastic stiffness. The difference between the initial and final torque was due to viscous and plastic stiffness. Elastic stiffness accounted for upwards of one half the total stiffness at maximum amplitude (Fig. 6).

\section{Physiological Variations}

Sex.-31 men were paired with 31 women of the $\frac{0}{2}$ same age (within one year) and their stiffness com- ĩ pared. There was a highly significant difference between the stiffness in the men and in the women, $\dot{\omega}$ the men showing greater stiffness (Table I).

TABLE I

COMPARISON OF STIFFNESS (kilogram-centimetres/radian) AT \pm 0.44 RADIANS MAXIMUM ROTATION IN 31 MALES AND 31 FEMALES MATCHED TO WITHIN \pm 1 YEAR OF AGE

\begin{tabular}{|c|c|c|c|c|c|}
\hline & & & Stiffne & cm./rad.) & 응 \\
\hline & & & At Flexion & At Extension & $\leq$ \\
\hline Male & $\cdots$ & $\begin{array}{l}\text { Mean } \\
\text { S.D. } \\
\text { S.E.M. }\end{array}$ & $\begin{array}{l}2 \cdot 31 \\
0 \cdot 81 \\
0 \cdot 15\end{array}$ & $\begin{array}{l}2 \cdot 96 \\
1 \cdot 30 \\
0 \cdot 24\end{array}$ & $\stackrel{2}{?}$ \\
\hline Female & $\cdots$ & $\begin{array}{l}\text { Mean } \\
\text { S.D. } \\
\text { S.E.M. }\end{array}$ & $\begin{array}{l}1 \cdot 52 \\
0 \cdot 81 \\
0 \cdot 15\end{array}$ & $\begin{array}{l}1 \cdot 70 \\
0 \cdot 68 \\
0 \cdot 12\end{array}$ & \\
\hline Differen & & . & $P<0.001$ & $P<0.001$ & \\
\hline
\end{tabular}

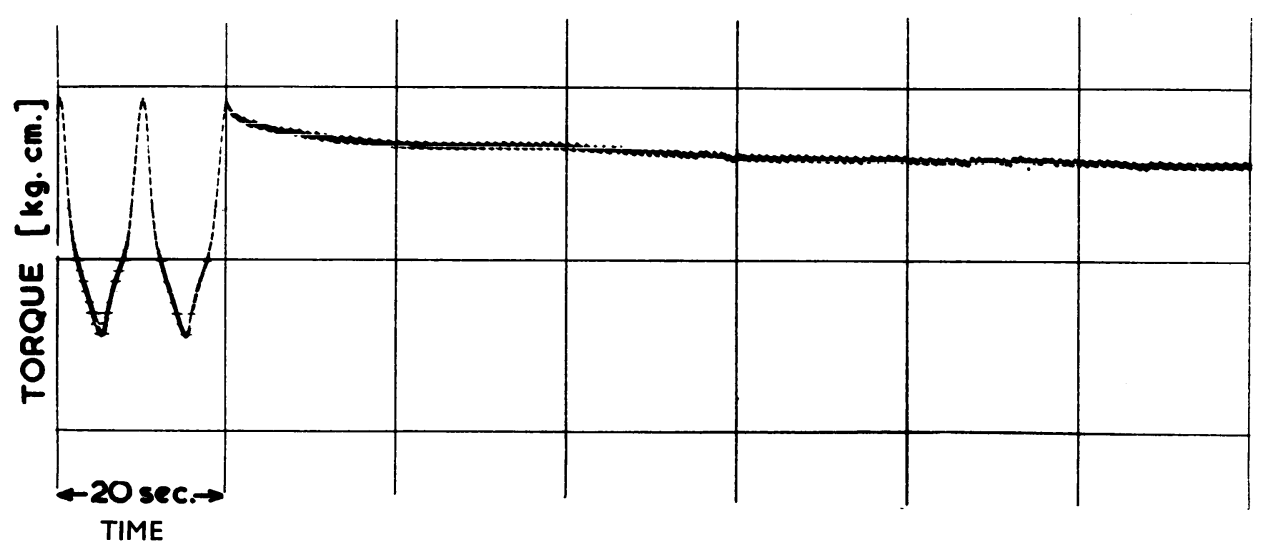

Fig. 7.-Stress relaxation in a normal subject.

Ordinate: Torque, $1.667 \mathrm{~kg}$.-cm. per division.

After a displacement of 0.67 radians flexion the torque decreased from 1.55 to $1.00 \mathrm{~kg} .-\mathrm{cm}$. These data appear in Fig. 6 . 

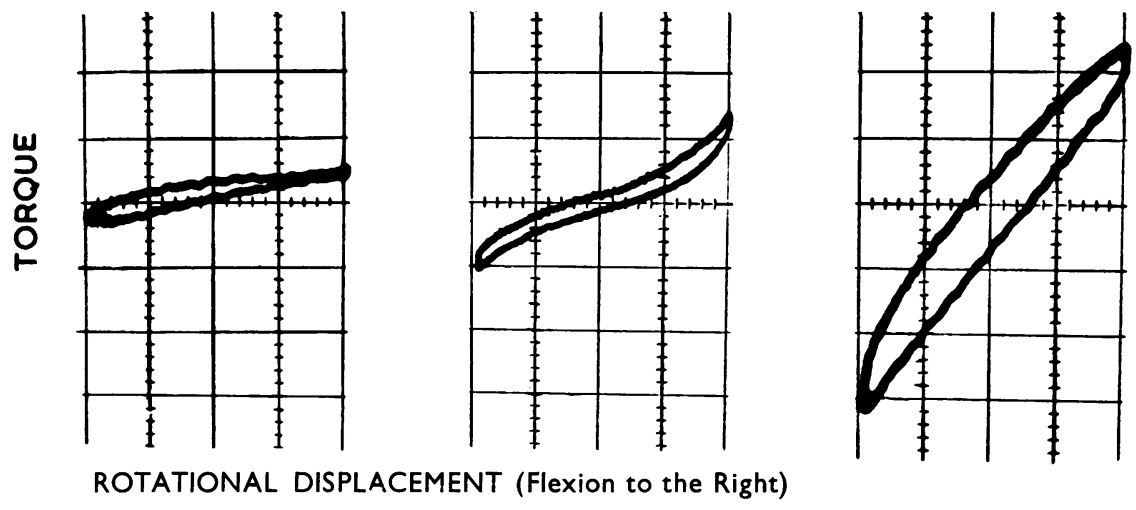

Fig. 8.-Effect of age on elastic stiffness.

Amplitude of rotation \pm 0.44 radians.

Progressive increase in stiffness with increasing age is indicated by steepening slopes.

Age.-There were significant differences in stiffness with age. Records from three females aged 6, 28, and 66 years are shown in Fig. 8. There was progressive increase of stiffness with advancing age as indicated by the steeper slopes of the curves.

Temperature.-To determine the effect of cold, three experiments were done on two subjects, in which the hand was immersed in ice water until the skin temperature fell to $18^{\circ} \mathrm{C}$. The temperature of the forearm muscles remained constant (recorded from an intramuscular thermistor needle). There was a 10 to 20 per cent. increase in stiffness on cooling.

To determine the effect of heat, the second metacarpophalangeal joints of two subjects were painted black and irradiated by an infra-red lamp to a surface temperature of $45^{\circ} \mathrm{C}$. while the surrounding tissue was shielded by aluminium foil. Stiffness was measured at this temperature and at intervals as the temperature fell to normal. There was a 20 cent. decrease in stiffness at $45^{\circ} \mathrm{C}$. compared with the stiffness at $33^{\circ} \mathrm{C}$. (Table II).

TABLE II

EFFECT OF INCREASING TEMPERATURE ON JOINT STIFFNESS (kilogram-centimetres/radian) IN TWO NORMAL SUBJECTS AT MAXIMUM EXTENSION

\begin{tabular}{|c|c|c|c|c|c|c|}
\hline \multirow{2}{*}{$\begin{array}{l}\text { Amplitude } \\
\text { of } \\
\text { Rotation } \\
\text { (rad.) }\end{array}$} & \multicolumn{3}{|c|}{ Subject 1} & \multicolumn{3}{|c|}{ Subject 2} \\
\hline & $\begin{array}{l}33 \cdot 5^{\circ} \\
\text { C. }\end{array}$ & ${ }^{45^{\circ}}$ & $\begin{array}{l}\text { Percentage } \\
\text { Decrease }\end{array}$ & $\begin{array}{l}33 \cdot 5^{\circ} \\
\text { C. }\end{array}$ & $\mathrm{C5}^{\circ}$ & $\begin{array}{l}\text { Percentage } \\
\text { Decrease }\end{array}$ \\
\hline $\begin{array}{l} \pm 0.53 \\
\pm 0.46 \\
\pm 0.40 \\
\pm 0.34\end{array}$ & $\begin{array}{l}4 \cdot 5 \\
4 \cdot 3 \\
4 \cdot 0 \\
3 \cdot 9\end{array}$ & $\begin{array}{l}3 \cdot 8 \\
3 \cdot 2 \\
3 \cdot 0 \\
3 \cdot 0\end{array}$ & $\begin{array}{l}16 \\
26 \\
23 \\
26\end{array}$ & $\begin{array}{l}3 \cdot 4 \\
3 \cdot 1 \\
3 \cdot 0 \\
2 \cdot 9\end{array}$ & $\begin{array}{l}2 \cdot 7 \\
2 \cdot 4 \\
2 \cdot 4 \\
2 \cdot 2\end{array}$ & $\begin{array}{l}21 \\
23 \\
25 \\
24\end{array}$ \\
\hline
\end{tabular}

Effect of Oedema.-To investigate the influence of local oedema, saline was injected in the region of the joint capsule and the effect on joint stiffness was measured. Two control series of tracings were recorded; then $1 \mathrm{ml}$. was injected over the extensor aspect, followed by further $3 \mathrm{ml}$. in this region; then $4 \mathrm{ml}$. were injected over the flexor aspect. After each injection a series of tracings was photographed at low $(0 \cdot 1$ c.p.s. $)$, medium (1 c.p.s.) and high frequencies $(1 \cdot 3$ c.p.s.) of rotation. After injection of $1 \mathrm{ml}$. into the extensor surface there was a 13 per cent. increase in stiffness on extension (Fig. 9).

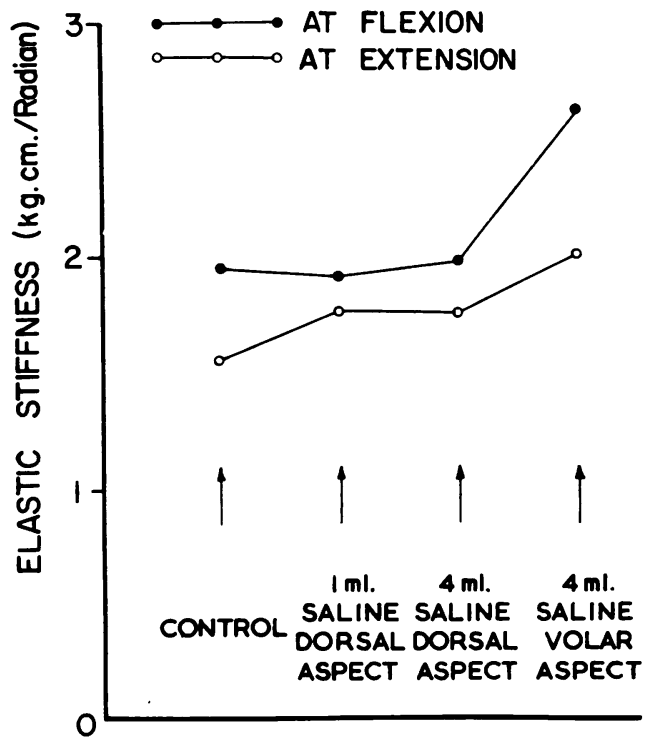

Fig. 9.-Effect of injecting saline subcutaneously around the joint. Saline injected into the extensor surface resulted in increased stiffness at extension, and that into the flexor surface produced increased stiffness at flexion. 
The injection of a further $3 \mathrm{ml}$. produced no further increase in stiffness. The injection of $4 \mathrm{ml}$. into the flexor aspect produced a 33 per cent. increase in stiffness on flexion and a 9 per cent. increase on extension. The same relationship was present at all frequencies of rotation.

\section{Connective Tissue Diseases}

Increased Stiffness.-It was of interest that in arthritic joints the relation between elastic, viscous, and frictional stiffness was the same as in normal joints. Only in severely damaged joints which showed marked clinical and radiographic deterioration could friction be demonstrated (Fig. 10).

Even in these joints frictional stiffness did not contribute significantly to joint stiffness, the major component being increased elastic stiffness (Table III).

$$
\text { TABLE III }
$$

TORQUE (kilogram-centimetres) REQUIRED TO OVERCOME ELASTIC, VISCOUS, AND FRICTIONAL STIFFNESS IN A BADLY DAMAGED ARTHRITIC JOINT AND IN A NORMAL JOINT AT AN AMPLITUDE OF \pm 0.53 RADIANS

\begin{tabular}{|c|c|c|c|c|}
\hline \multicolumn{2}{|c|}{ Stiffness } & Elastic & Viscous & Frictional \\
\hline \multirow{2}{*}{ Joint } & Arthritic ... & $4 \cdot 46$ & 0.42 & 0.05 \\
\hline & Normal ... & $2 \cdot 90$ & $0 \cdot 29$ & 0 \\
\hline
\end{tabular}

Increased stiffness was sometimes observed in patients with inactive rheumatoid arthritis which had previously involved the metacarpophalangeal joints. This was illustrated by the results obtained in three women, one in the fifth decade, and two in the sixth decade. All three had definite rheumatoid arthritis as defined by the criteria of the American Rheumatism Association (Ropes, Bennett, Cobb? Jacox, and Jessar, 1959). There was no clinicaP evidence of activity and the erythrocyte sedimenta tion rates were normal. One had mild ulnar. deviation at the metacarpophalangeal joints and another had a little residual swelling, but in none did the second metacarpophalangeal joint show any tenderness, pain, heat, redness, or limitation os movement within the range used in these experi 8 ments. All three, however, showed increased stiffness compared with groups of normal women of the same age.

Increased stiffness without active disease was als $\overrightarrow{\vec{H}}$ demonstrated in the joint of a man with chronie tophaceous gout. He was a 57-year-old white main who had had symptoms of gout for 15 years. At the time of testing he had tophi around the secon\& metacarpophalangeal joint. Friction was demon $\vec{\varkappa}_{\vec{H}}$ strated, but the force required to overcome it was very small compared with that required to overcome elastic stiffness, which proved to be the major component of his overall stiffness. Increased stiffness was also noted in a 42-year-old coloure ${ }^{\circ}$ woman with the chronic phase of the shoulder-hand syndrome.

Involvement of the second metacarpophalangeat joint by active rheumatoid disease increased elasti stiffness. Records were taken from a 42-year coloured woman with active rheumatoid arthrî? of 5 months' duration whose arthritis subsided oo treatment with prednisolone. They showed marked decrease in stiffness following remission induced by prednisone, although it had not reverteg to the normal pattern for a woman of this age.

Connective tissue diseases not involving the joint
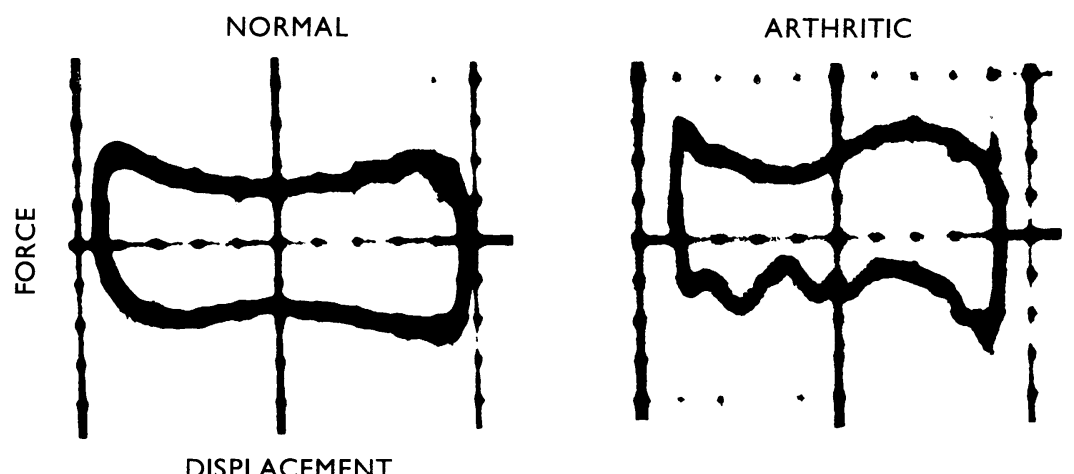

Fig. 10.-Demonstration of friction in a severely damaged joint.

Forces due to elasticity and viscosity have been attenuated to permit a 20 -fold increase in the force scale (see text). The increased ampli

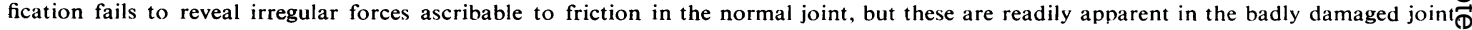


directly caused increased joint stiffness subjectively and objectively. Two white women, both aged 39 years, who complained of stiffness of the hands, showed changes of systemic sclerosis on examination. The process was more advanced in one than in the other, but both showed elastic stiffness considerably greater than normal white women of their age (Table IV).

TABLE IV

STIFFNESS (kilogram-centimetres/radian) AT $\pm \mathbf{0} \cdot 47$ RADIANS MAXIMUM ROTATION IN TWO PATIENTS WITH SYSTEMIC SCLEROSIS COMPARED WITH NORMAL WOMEN OF THE SAME AGE GROUP

\begin{tabular}{|c|c|c|c|c|}
\hline & \multirow{2}{*}{\multicolumn{2}{|c|}{ Subjects }} & \multicolumn{2}{|c|}{ Stiffness (kg.-cm./rad.) } \\
\hline & & & At Flexion & $\overline{\text { At Extension }}$ \\
\hline \multirow{2}{*}{$\begin{array}{l}\text { Systemic } \\
\text { Sclerosis }\end{array}$} & \multicolumn{2}{|c|}{ Woman (aged 39 years) } & $2 \cdot 6$ & $5 \cdot 5^{*}$ \\
\hline & \multicolumn{2}{|c|}{ Woman (aged 39 years) } & $5 \cdot 0^{*}$ & $11 \cdot 0^{*}$ \\
\hline Normal & $\begin{array}{l}10 \text { Women } \\
\text { (aged 35-44 } \\
\text { yrs) }\end{array}$ & $\begin{array}{l}\text { Mean } \\
\text { S.D. }\end{array}$ & $\begin{array}{l}1 \cdot 72 \\
0 \cdot 84\end{array}$ & $\begin{array}{l}1 \cdot 76 \\
0.46\end{array}$ \\
\hline
\end{tabular}

* Significantly stiffer than in normal women.

Decreased Stiffness.-Decreased elasticity of the skin and hypermobility of the joints is found in certain hereditary connective tissue disorders. Two patients, a girl aged 16 years and a man aged 39 years, with Ehlers-Danlos syndrome showed decreased elastic stiffness at the joint. Further studies on the man revealed an increased rate of stress relaxation as measured by its half time.

These changes were less marked in patients with Marfan's syndrome. In the six patients studied the results were not significantly different from those in groups of normal subjects of comparable age.

\section{Discussion}

Joint stiffness has previously been measured by inexact methods, ranging from the subjective feeling of the patient (Cobb, Warren, Merchant, and Thompson, 1957) to the limitation of motion demonstrable by the observer (Ellis and Bundick, 1956; Williams, 1957). An extensive review of the literature has revealed that little has been done to measure joint stiffness with precision, either quantitatively or qualitatively (Wright and Johns, 1960b). We have described a method of assessing joint stiffness quantitatively in precise physical terms. Furthermore, the method characterizes the nature of the stiffness qualitatively by the physical terms elastic, viscous, frictional, inertial, and plastic
(Wright and Johns, 1960b). Reproducibility of results is good if care is taken in aligning the axes of rotation of the joint and the apparatus.

Although passive movements of tendons and muscles contribute to the stiffness measured at normal and diseased joints, it should be emphasized that no active contraction of muscle (voluntary or reflex) is found electromyographically. Moreover, the contribution of passive muscle and tendon movement does not obscure alterations in joint stiffness produced by physiological and pathological changes limited to the region of the joint (Wright and Johns, 1960a).

While active muscular contraction is not present in normal subjects, it may be of importance in the joint stiffness of certain neuromuscular disorders such as Parkinsonism and myotonia congenita. This type of stiffness is easily measured by these methods (Wright and Johns, 1960a). Thus, this technique measures objectively what the patient experiences subjectively in terms of stiffness at the joint whether due to arthritis or other disorders.

Voluntary muscular contractions occasionally occur during the course of an experiment. Such contractions produce distortions of the tracing which are readily apparent, and these records are disregarded.

Normal Subjects. - It is impossible to compare the various types of stiffness directly since they differ dimensionally. Direct comparison is possible, however, if one considers the force (torque) required to overcome the various types of stiffness at physiological speeds. In normal subjects the force required to overcome elastic and plastic stiffness is the most important, accounting for 90 per cent. of the total force required. Viscous stiffness ranks next in order of importance ( 9 per cent.), while inertial stiffness is negligible at the accelerations used. Indirect measurement has shown that, at the maximum acceleration used for the measurement of elastic stiffness in these experiments $(17 \cdot 3$ radians per second ${ }^{2}$ ), the torque required to overcome inertial stiffness is one-hundredth of that needed to overcome elastic stiffness (Wright and Johns, 1960a). No friction is demonstrable in normal joints.

The joint, in common with other visco-elastic substances, exhibits non-linear elasticity. Increasing stiffness is observed with greater amplitudes of rotation. This may be due to the property (well exemplified in a rubber band) of the capsule becoming stiffer the further it is stretched. It may, however, be due to the fact that stiff elastic elements, such as ligaments and joint capsule, may be slack 
until the extremes of joint motion are approached. The anatomy of the metacarpophalangeal joint with the tight apposition of tendons forming an integral part of the joint capsule suggests that the former explanation is probably the correct one.

Stress relaxation is easily demonstrable. With abrupt movements of the joint, the total force wanes with the passage of time due to stress relaxation. The reduction in force is more rapid at first, and becomes progressively slower. As infinite time is approached, only elastic force remains. Comparison of the initial with the final force indicates that under these circumstances elasticity contributes approximately half the total stiffness and plasticity together with some viscosity the remainder. Thus, the major single component in the stiffness of the normal joint is elasticity.

Physiological Variations.-There are marked differences in stiffness between the sexes, men being significantly stiffer than women. Since stiffness is expressed per joint, and since the joints of men are larger than those of women, joint size may in part explain this difference.

With advancing age differences in stiffness are apparent. The older the subjects, the more stiff they become. Again, joint size may contribute to the changes observed up to attainment of maturity. Size cannot explain increases in stiffness occurring after maturity. These increases may be related to changes in collagen of which the joint capsule is largely composed. It is well known that there is alteration of collagen with advancing age, shown by increase in fibril width (Gross, 1950), greater thermal contraction (Verzár, 1957), decreased susceptibility to collagenase (Keech, 1955; Tunbridge, 1957) and increased cross-linking (Verzár, 1957).

The effect of temperature changes localized to the joint is shown by increased stiffness at lower temperatures and decreased stiffness at higher temperatures. The latter effect probably accounts for the subjective benefit derived by arthritic patients from local heat such as paraffin-wax baths. The contention that a significant part of the stiffness measured at the joint is attributable to the joint itself is supported by these results. Here local temperature changes in the joint produce clear changes in stiffness while the temperature of more remote structures such as muscles remains constant.

The ability of changes localized to the region of the joint to produce changes in joint stiffness is further exemplified by the effect of the injection of saline in the region of the joint capsule. Elastic stiffness was increased by an injection of 1 to $4 \mathrm{ml}$. subcutaneously. The fact that saline injected into the extensor aspect caused an increase in stiffness oक्ष extension rather than on flexion, and that saline injected into the flexor surface caused a greate? increase in stiffness on flexion than on extensiop suggests that the effect is largely mechanical. These. results illustrate the role that oedema may plas in the stiffness of inflammatory arthritis. They als $\bar{Q}$ raise the possibility that oedema is responsible foo the morning stiffness which is so characteristic feature of rheumatoid arthritis, although other o\$ our studies suggest that this is more likely to be a phenomenon of muscle weakness than of joint stiffness (Wright, 1959).

Connective Tissue Disorders.-It was surprising to find that in arthritic disorders elastic, viscous and frictional stiffness maintain the same relative importance as in normal subjects. Even in the most badly-damaged joints the force required to overcome frictional stiffness accounts for only 1 per cent. of the overall stiffness. Similarly? although viscous stiffness is slightly increased, the force required to overcome it amounts to onl 9 per cent. of the force required to overcome overa $\mathbb{P}$ stiffness. It is of interest that not only patients with active rheumatoid arthritis but also some witl inactive disease show increased elastic stiffnessoat the joint. This is probably due to residual changes in the joint capsule. The cause of the stiffness experienced by patients with degenerative join disease is apparently due to changes in the joing capsule, whether primary or secondary, and noథ to damaged joint surfaces, for increased elasti $\vec{E}$ stiffness is the major factor in this joint stiffness. 3

Involvement of tissue surrounding the join capsule may influence joint stiffness. Thus it is. probably involvement of skin and subcutaneou\& tissue in patients with systemic sclerosis which produces the marked increase in elastic stiffness There was no radiological evidence of bone or join involvement in our patients, although little is knowi about changes in the joint capsule in this disease.

Decreased elastic stiffness was noted in certai $\frac{}{P}$ hereditary connective tissue disorders, such as Ehlers-Danlos syndrome and Marfan's syndrome More detailed studies of the elastic stiffness anfy stress relaxation may yield information concerning the site of the basic lesion in these diseases, a subject about which there is remarkable confusion (Jansenf 1955; McKusick, 1959). Some of this confusio may have arisen from the clinical practice of firs stating that the skin of patients with such disorder shows increased elasticity (Jansen, 1955; Zaidi, 1959) and then discussing the pathological lesion in terms of the physical causes of hyperelasticity 
In fact, in physical terms, the skin shows decreased elasticity (or elastic stiffness).

\section{Summary}

Using a method of measuring joint stiffness in precise physical terms, it has been shown that in normal and arthritic joints elastic stiffness is the major component in overall joint stiffness. There is significant plastic stiffness. Frictional and inertial stiffness are negligible, and viscous stiffness is small.

A study of 62 white subjects without arthritis showed a significantly increased elastic stiffness in men, and increasing stiffness with advancing age in all subjects.

Increased stiffness is produced by cooling the joint, by the injection of saline around the capsule, in patients with active rheumatoid arthritis and in some with inactive disease. Increased stiffness is also found in chronic tophaceous gout involving the joint and in systemic sclerosis.

Decreased stiffness follows the warming of the joint, and is also found in certain hereditary connective tissue disorders.

\section{REFERENCES}

Cobb, S., Warren, J. E., Merchant, W. R., and Thompson, D. J. (1957). J. chron. Dis., 5, 636.

Ellis, F. E., and Bundick, W. R. (1956). A.M.A. Arch. Derm., 74, 22.

Gross, J. (1950). Amer. J. Path., 26, 708.

Jansen, L. H. (1955). Dermatologica (Basel), 110, 108.

Keech, M. K. (1955). Ann. rheum. Dis., 14, 19.

McKusick, V. A. (1959). Amer. J. Med., 26, 283.

Ropes, M. W., Bennett, G. A., Cobb, S., Jacox, R., and Jessar, R. A. (1959). Ann. rheum. Dis., 18.49.

Tunbridge, R. E. (1957). Ibid., 16, 6.

Verzár, F. (1957). "The Ageing of Collagen", in "Connective Tissue, a Symposium organized by the C.I.O.M.S.”, ed. R. E. Tunbridge, p. 208. Blackwell, Oxford.

Williams, P. O. (1957). Rheumatism, 13, 13.

Wright, V. (1959). Clin. Sci., 18, 17.

, and Johns, R. J. (1960a). Bull. Johns Hopk. Hosp., 106, 215.

(1960b). Arthr. and Rheum., 3, 328.

Zaidi, Z. H. (1959). Brit. med. J., 2, 175.

Discussion.-Dr. A. G. S. Hill (Stoke Mandeville) said that many rheumatoid patients were stiff in the evening when grip became weaker.

DR. WRIGHT agreed that he had found that in many subjects the power of grip diminished after 10 p.m. whether they went to bed or not.
Prof. S. J. Hartfall (Leeds) asked what happened to grip and stiffness in rheumatoid patients on night work.

DR. WRIGHT said he had investigated one night worker, a hospital porter, who did not suffer from rheumatoid arthritis. He reversed his grip-rhythm and his temperature rhythm very rapidly. Since temperature rhythm usually takes 3 or 4 days to reverse, he wondered whether this man was an unusually labile subject as a result of being on shift work.

Prof. J. H. Kellgren (Manchester) said that not all rheumatoid patients were stiff. There were also those with destroyed and excessively mobile joints. He asked whether they had made any observations on such patients, and which joint had been used for their measurements.

DR. WRIGHT replied that no observations had been made on that type of patient. The joint used had been the metacarpophalangeal joint.

DR. J. H. GLYN (London) asked whether there was any similarity between rheumatoid and athletic stiffness.

Dr. WRIGHT replied that rheumatoid stiffness was probably not caused by changes in the muscles, whereas athletic stiffness was probably primarily muscular.

Prof. E. G. L. Bywaters (London) asked whether any measurements had been made under anaesthesia.

Dr. WrIGHT replied that he had not investigated patients during anaesthesia.

Analyse quantitative et qualitative de l'enraidissement articulaire chez des sujets normaux et chez les sujets atteints de maladies du tissu conjonctif

\section{RÉSUMÉ}

Grâce à un procédé permettant de mesurer l'enraidissement en termes physiques précis, on a pu démontrer que dans des articulations tant normales qu'arthritiques la rigidité élastique est le composant principal de l'enraidissement articulaire total. La rigidité plastique est significative. Les rigidités de friction et d'inertie sont négligeables et la rigidité visqueuse est minime.

Une étude de 62 sujets de race blanche non arthritiques a démontré une augmentation significative de l'enraidissement chez les hommes et une augmentation progressive chez tous les sujets au fur et à mesure que leur âge avançait.

L'augmentation de l'enraidissement par refroidissement de l'articulation (par injection péricapsulaire d'eau physiologique) survient chez des malades atteints d'arthrite rhumatismale évolutive et chez quelques sujets en période de rémission. L'augmentation de l'enraisidsement apparaît aussi dans des cas de goutte tophacée chronique impliquant une articulation et aussi dans des case de sclérose généralisée.

Une diminution de l'enraidissement survient après un réchauffement de l'articulation et aussi dans certaines affections héréditaires du tissu conjonctif. 
Análisis cuantitativo $y$ cualitativo de la rigidez articular en individuos normales $y$ en pacientes con enfermedades del tejido conectivo

\section{Sumario}

Empleando un método que proporciona una medida en términos físicos precisos de la rigidez articular, se ha demostrado que en articulaciones tanto normales como artríticas la rigidez elástica es el componente principal de la rigidez articular total. La rigidez plástica es significativa. La rigidez de fricción y de inercia son negligibles y la rigidez de viscosidad es pequeña.
Un estudio de 62 individuos de raza blanca que ng padecían artritis demostró un incremento significativळ de la rigidez en los varones y aumento progresivo ef todos los individuos a medida que la edad avanza.

Aumento de la rigidez por enfriamiento de la articu? lación (por inyección pericapsular de suero salino) sé. presenta en enfermos con artritis reumatoide evolutiva $\mathrm{y}$ en algunos en periodo de remisión. Aumento de lfé rigidez apareció también en casos de gota tofaceఖ crónica afectando la articulación estudiada y en esclerosi generalizada.

Disminución de la rigidez aparece después del calenta miento de la articulación y también en determinada@ afecciones hereditarias del tejido conectivo. 